\section{GERTRUDIS, TULA, LA PEREGRINA Y OTRAS FICCIONES DEL YO}

María A. Salgado

The University of North Carolina at Chapel Hill masal@live.unc.edu

Cómo citar este artículo/Citation: Salgado, M. A. (2014). "Gertrudis, Tula, La Peregrina y otras ficciones del yo". Arbor, 190 (770): a182. doi: http://dx.doi.org/10.3989/ arbor.2014.770n6003

Recibido: 12 febrero 2014. Aceptado: 30 octubre 2014.

RESUMEN: La Autobiografía, además de las cartas y los poemas de Gertrudis Gómez de Avellaneda, contienen varios retratos literarios personales en los que dejó plasmada una gama de versiones de sí misma. Este ensayo examina las varias posturas que adopta y su posible significación.

PALABRAS CLAVE: Gertrudis Gómez de Avellaneda; Romanticismo; (auto)retrato literario; autobiografía; género epistolar.

\section{GERTRUDIS, TULA, LA PEREGRINA AND OTHER FICTIONS OF THE SELF}

Copyright: @ 2014 CSIC. Este es un artículo de acceso abierto distribuido bajo los términos de la licencia Creative Commons Attribution-Non Commercial (by-nc) Spain 3.0.

ABSTRACT: Gertrudis Gómez de Avellaneda's Autobiografía, her letters, and her poems include a number of personal literary portraits in which she shapes several versions of her own self. This essay examines the various poses she adopts and their possible significance.

KEYWORDS: Gertrudis Gómez de Avellaneda; Romanticism; literary (self)portrait; autobiography; epistolary genre. 
En las letras en lengua española la tendencia a entronizar el yo del autor en retratos literarios que culmina en el Modernismo se inicia en la época romántica. Es curioso, empero, que no obstante la primacía de tal preferencia, manifiesta en la abundancia de textos autobiográficos escritos por tantos románticos, la mayoría de ellos no parece haberse sentido atraído por la idea de escribirse en una estampa personal. ${ }^{1}$ La reticencia pudiera atribuirse a que en esa época el presunto realismo de un retrato no se avenía con la espiritualidad y el idealismo románticos, tal como se desprende de una carta que Gertrudis Gómez de Avellaneda (1814-1873) escribió en 1853 a uno de sus admiradores, el escritor y político español Antonio Romero Ruiz:

Solo me resta decirle que tendré mas complacencia en leer sus escritos que curiosidad por averiguar el nombre del autor, ó por ver su figura fea ó hermosa, también soy algo escéntrica y aun estravagante: no presto gran valor á los nombres, y en cuanto à la figura, es tanto lo que me enoja que hasta las ideas mas sublimes necesiten formas, siempre inferiorísimas à ellas, que he llegado à cobrar cierta antipatía por todo lo que no es vago, indeterminado, y lo menos material posible. De buena gana haría yo que las gentes de talento se pasasen sin cuerpo, aun cuando pudieran adornarse con el del mismo Apolo. (Avellaneda, 1975, p. 11) ${ }^{2}$.

Si semejante aversión impidió que Tula se retratase en un texto independiente, claramente identificado con su persona, no le impidió escribir innumerables obras autobiográficas y bosquejar en ellas una serie de retratos y breves instantáneas de su yo que en distintos momentos de su vida le permitieron colocar en primer plano aquellas aristas históricas de su polifacética e idiosincrásica persona que en ese momento le interesaba destacar. ${ }^{3}$ Estudiar tales bosquejos, profundizando en la significación de las posturas que adopta, es la tarea que llevo a cabo en este ensayo, si bien contextualizo antes a grandes rasgos los parámetros del retrato literario para examinar después en orden cronológico algunas estampas de la escritora cubana.

Muchos han sido los críticos y teóricos que se han ocupado de la escritura biográfica y autobiográfica, pero muy pocos han fijado su atención en los más breves y menos ostentosos retratos y autorretratos literarios. No es de hecho hasta que Hélène Dufour publica en 1997 su exhaustivo libro Portraits, en phrases. Les recueils de portraits littéraires au XIXe siècle, que se puede contar con una fuente que trace la evolución histórica del género, al menos en Francia. Dufour señala que aunque retratos literarios se han escrito a lo largo de la historia, su auge, manifestación de una profunda corriente individualista, no tuvo lugar hasta el siglo XIX, y acredita a Charles Augustin Sainte-Beuve (1804-1869)--y su colección de semblanzas y críticas literarias Critiques et portraits littéraires (1832)--tanto con ser el origen del género moderno como con dar el nombre de "retratos" a este tipo de textos (Dufour, 1997, pp. 8-9). En la literatura hispana, el apogeo del género también tuvo lugar en el siglo XIX, si bien algo más tarde; no fueron los románticos sino los modernistas, influidos por la "fuerte corriente individualista" romántica y por la literatura francesa, quienes lo difundieron. Los raros (1896) de Rubén Darío (1867-1916) divulgó la tendencia a fundir la persona y la obra literaria que predominaría en los retratos y autorretratos de finales del XIX y principios del XX. Gómez de Avellaneda antecede al Modernismo, pero como genuina romántica, participó de las tendencias individualistas que señala Dufour, y, como Darío, se sintió movida a literaturizar su yo en una variedad de estampas en prosa y en verso que se adelantaron a lo que sería después el retrato modernista.

Los textos autobiográficos de la autora cubana son varios, pertenecen a distintos géneros literarios y fueron escritos con diversos propósitos. ${ }^{4}$ Ángeles Ezama Gil estudia los juicios críticos que se han escrito sobre ellos, concentrándose en los cinco más debatidos--“Memorias (1838), Autobiografía (1839), cartas a Neira (1843-1844), 'Apuntes biográficos' (1850), [y] 'Mi última excursión a los Pirineos' (1860)" (Ezama Gil, 2009, p. 9)--y explicando las circunstancias de su producción:

Los dos más tempranos fueron concebidos para la escritura privada y sólo la posteridad les ha dado una fama que nunca pretendió la autora. Los tres últimos, que vieron la luz pública en vida de la escritora, corresponden al periodo en que Gómez de Avellaneda es ya una autora consagrada. [. . .] Sin embargo, estos tres relatos se editaron en circunstancias muy diversas: el primero con el permiso de la autora pero no en la forma requerida (son unas notas biográficas, no un relato voluntariamente autobiográfico--forma en que puede ser leído--ni un artículo biográfico--forma en que debió haberse editado), el segundo se publicó en forma de artículo biográfico (elaborado por Neira a partir de las cartas de Avellaneda), y el tercero tal y como la autora lo escribió para darlo a la prensa (pero más que relato autobiográfico es una relación de viaje) (Ezama Gil, 2009, p. 9). 
De las fuentes mencionadas por Ezama, estudio la Autobiografía de 1839 y las cartas a Neira; examino además las Cartas a Cepeda y las Cartas inéditas en el Museo del Ejército, así como también varias poesías escritas con el evidente propósito de afirmar su propia visión de su persona y personalidad históricas. En estos textos Avellaneda se dirige a destinatarios históricos específicos y entabla un diálogo con ellos en que implícita o explícitamente articula su intención de superponer su visión de sí misma sobre la que pueda haber formado su oyente o los (pre) juicios de la sociedad.

Tal vez su retrato más largo y complejo sea el primero, el que traza en la Autobiografía, un texto cuyo género literario es por demás problemático. El título partió no de ella sino de Lorenzo Cruz de Fuentes, su editor, cuando lo publicó en 1907, sesenta y ocho años después de haber sido escrito. Avellaneda lo llama un "cuadernillo", término más en consonancia con el carácter aparentemente espontáneo y familiar de un retrato escrito a los veinticinco años, en forma de nueve nerviosas entradas que trazó entre la una de la noche del 23 de julio de 1839 y la tarde del 27, y en las que (con)funde hasta cuatro estilos intimistas: los comentarios sobre el presente de la escritura asociados al diario, la narración de vida retrospectiva y cronológica de la (auto)biografía, la sincera veracidad de la revelación a su dios de la confesión, y la inmediatez del diálogo de la carta. Lo escribe para Ignacio de Cepeda, un joven de veintitrés años--de quien según sus biógrafos y sus propias palabras estaba totalmente enamorada--con la intención explícita de que él la conociera, y estipulando condiciones de secreto que él nunca cumpliría:

Es preciso ocuparme de V.; se lo he ofrecido; $y$, pues, no puedo dormir esta noche, quiero escribir: de V. me ocupo al escribir de mí, pues sólo por V. consentiría en hacerlo.

La confesión, que la supersticiosa y tímida conciencia arranca á una alma arrepentida á los pies de un ministro del cielo, no fué nunca más sincera, más franca, que la que yo estoy dispuesta á hacer á V. Después de leer este cuadernillo, me conocerá $V$. tan bien, ó acaso mejor que á sí mismo. Pero ecsijo dos cosas. Primera: que el fuego devore este papel inmediatamente que sea leido. Segunda: que nadie más que $\mathrm{V}$. en el mundo, tenga noticia de que ha existido. (Avellaneda, 1907, p. 13).

El cuadernillo y las cartas a Cepeda que Cruz de Fuentes incluye en esta edición, además de las que añade en una segunda de 1914, son sin duda los textos autobiográficos de Avellaneda que mayor atención crítica han recibido. Cruz de Fuentes dice publicarlos para dar a conocer la faceta íntima de la autora, la que revela en "la autobiografía y las cartas" (Avellaneda, 1907, p. 4). El retrato de sí misma que Tula traza en su Autobiografía no es ni tan inocente como sugiere Cruz de Fuentes ni tan sincero como ella protesta: toda escritura es ficción. Roxana Pagés-Rangel, entre otros, lo señala, al mostrar "en qué medida los reclamos de 'sinceridad' y 'espontaneidad,' que en general están adscritos a la literatura femenina, son falaces: la autora [Avellaneda] construye una imagen de sí misma dirigida hacia la seducción del lector y maneja todo tipo de estrategias literarias con el propósito de crear un texto que pone en entredicho la noción de 'naturalidad' y en el que se manifiesta su conciencia de la escritura como elaboración" (Pagés-Rangel, 1997, p. 26). No obstante la ostensible "falsedad" histórica del cuadernillo, los juicios críticos oscilan entre los que aceptan la "sinceridad" que profieren la autora y su editor y los que leen en las palabras de la autora posturas alternas. La opinión de la también escritora Emilia Pardo Bazán fue cautelosa, indica que aunque el retrato es sincero, su "verdad" no está tanto en lo que dice como en lo que desvela la postura que adopta: "Cada cual dice de sí lo que más se aparece [sic] al tipo que nos forjamos y al cual desearíamos parecernos exactamente; y ya sólo con este deseo revelamos tanto de nuestra alma, que no hay confesión más elocuente ni más verídica" (Ezama, 2009, p. 89). Para Emil Volek, la protagonista no solo escribe una postura romántica, sino que la vive: "Al escribir su primera misiva al 'Compañero de desilusión' que la ha deslumbrado, la joven cubana, que acaba de cumplir veinticinco años (pero confiesa veintitrés), despliega una perfecta pose romántica, donde el concepto de amor inalcanzable se trastrueca en la embriaguez del desengaño, del tedio y del gozo en el sufrimiento--pose que, además, vive" (Volek, 2004, pp. 9-10; énfasis en el original). Phyllis Zatlin describe un yo en abierto combate con sus circunstancias: "Al leer la autobiografía de Avellaneda, el lector se encuentra con una joven en lucha--en lucha con la sociedad, con sus parientes, consigo misma--. Una persona reñida con su ambiente, Avellaneda no puede esperar que la entiendan todos los que piensan que todas las mujeres deben llevar vidas iguales" (Zatlin, 1981, p. 97). Dentro de esta misma línea, Brígida Pastor deduce que el yo del cuadernillo combate la opresión de la mujer, que entiende "[como] ejemplo representativo de la expresión genuina de su identidad femenina y a la vez 
eco de su constante lucha como mujer dentro de una cultura hegemónica masculina" (Pastor, 2000, s.p.). Y en otro giro adicional, Alexander Selimov sostiene la ficción de la postura del yo, aduciendo que Tula se escribe como un personaje de novela romántica: "está dotado de todos aquellos valores que para un héroe de novela romántica se asocian con el sublime ideal femenino: la inocencia, la pureza, el talento. La protagonista se perfila como ángel de amor, ora melancólica, ora apasionada, pero siempre sincera y natural. Es una joven sensible, talentosa, tierna, pero sobre todo desgraciada, víctima del mal hado y de la hostilidad ajena" (Selimov, 1999, p. 36).

Las múltiples opiniones críticas--de las que cito tan solo una muestra-- y su diversidad, no impide que todas sean válidas y tampoco que sean tan definitivas como para impedirme profundizar en la que más me interesa, el retrato como acto de seducción, que han señalado ya varios estudiosos, entre ellos Pagés-Rangel y con anterioridad Susan Kirkpatrick (1989, p. 136). El retrato que traza Avellaneda en su Autobiografía está diseñado sin duda para seducir a su amado desde una postura que ella imagina seductora. Tal como ella se describe, las circunstancias familiares que realza en su historia son tan aristocráticas, nobles y correctas como las de Cepeda, y su persona y personalidad no desmerecen de las de él en educación, sensibilidad e intelecto; es, sobre todo, una mujer en busca del amor, lo que demuestra narrando su insistente búsqueda de ese amado ideal que soñó encontrar en los previos lances amorosos que enumera para Cepeda y que ahora está segura de haber hallado en él ${ }^{5}$.

Avellaneda inicia su retrato con un pacto de verismo. Afirma la sinceridad y trasparencia de su escrito equiparando la postura desde la que narra su persona con la de un "alma arrepentida" que se acerca al sagrado rito de la confesión ${ }^{6}$. Rito que inicia construyéndose un pasado que coloca su cubanía en primer plano, subrayando tanto la faceta romántica de exótica extranjera implícita también en su nombre de pluma, La Peregrina: "V. sabe, que he nacido en una ciudad del centro de la Isla de Cuba" (Avellaneda, 1907, p. $14)^{7}$, como la alcurnia de su ascendencia: "Cuando comencé á tener uso de razón, comprendí [. . .] que mi familia materna ocupaba uno de los primeros rangos del país, que mi padre era un caballero y gozaba toda la estimación que merecía por sus talentos y virtudes, y todo aquel prestigio que en una ciudad naciente $y$ pequeña gozan los empleados de cierta clase" (Avellaneda, 1907, p. 14). Se conduele después por la orfandad en que la deja la pronta muerte de su padre, soledad que agrava el segundo matrimonio de su madre y que presidirá su vida. Describe sin embargo una infancia placentera, realzando su refinada y culta educación y el cariño que la rodeaba y trazando una breve instantánea de su yo-niña que subraya su temprana diferenciación de la norma así como su propensión a la nostalgia:

Dábaseme la más brillante educación que el país proporcionaba, era celebrada, mimada, complacida hasta en mis caprichos, y nada experimenté que se asemejase á los pesares en aquella aurora apacible de mi vida.

Sin embargo, nunca fui alegre y atolondrada como lo son regularmente los niños. Mostré desde mis primeros años afición al estudio y una tendencia á la melancolía (Avellaneda, 1907, p. 16) ${ }^{8}$.

Insiste después en la prominente posición social de su familia y en el romántico y apasionado carácter que la domina, mostrando que prefirió su independencia sobre la seguridad que le hubieran proporcionado un matrimonio sin amor y la herencia familiar. Relata sus devaneos amorosos, el compromiso de casamiento que fragua su familia, y al que asiente en la inocencia de sus quince años pero que rechaza dos años más tarde, escindida entre ese novio sin dotes intelectuales que no ama y su atracción hacia un culto joven cuya amistad promete florecer en un romance. El escándalo de la ruptura, fomentado por la envidia de sus parientes, mueve al abuelo a desheredarla. Revivir la desilusión causada por el egoísmo de familiares y amigos le arranca lágrimas, y la mueve a interrumpir su narración para buscar apoyo en Cepeda, retratándose en la romántica postura de víctima incomprendida, pero que espera serlo de él, esa alma gemela a quien narra la injusticia que se le ha hecho, aunque--coqueta incorregible--le interroga después sobre si él será su alma gemela:

Estas fueron, ioh Cepeda!, estas las primeras lecciones que me dio el mundo: Esto encontré, cuando inocente, pura, confiada, buscaba amor, amistad, virtudes y placeres; i inconstancia! iperfidia! isórdido interés! jenvidia! crimen, crimen y nada más. [. . .]

Cepeda!, querido Cepeda! ¿Será cierto que V. siente como yo cuan poco vale este mundo y sus corrompidos placeres?; ¿no será V. otra nueva decepción para mí?; ¿quién me asegura que no es $\mathrm{V}$. un hipócrita?; ¿quién me garantiza su sinceridad?... (Avellaneda, 1907, pp. 28-29). 
Concluido el aparte, Tula vuelve al conflicto familiar narrando que este no se resuelve hasta que el padrastro les lleva a vivir en Santiago de Cuba. Allí se siente renacer en un ambiente culto y ameno que la acepta y celebra, con nuevos pretendientes que compiten por su atención:

Tube en aquella ciudad una aceptación tan lisonjera, que á los dos meses de estar allí ya no era yo una forastera. Jamás la vanidad de una mujer tubo tantos motivos de verse satisfecha. [. . .]

Hice algunos versos que fueron celebrados con entusiasmo; entreguéme á las diversiones, en las cuales era deseada y colmada de obsequios. V. supondrá que no me faltaron aspirantes: tengo algún orgullo en decirlo: los jóvenes más distinguidos del país se disputaban mi preferencia. Ninguno, empero, la consiguió esclusiva. (Avellaneda, 1907, p. 30).

El oasis de tranquilidad fue corto. El padrastro, deseoso de regresar a su nativa Galicia, y secundado por la joven Tula que ansiaba conocer la patria de su padre, logró convencer a la madre para mudarse a España. Narra la tristeza de dejar su tierra, la fascinación del viaje y de su breve estadía en Burdeos. La llegada a La Coruña la devuelve a una realidad enajenante. La pacata sociedad gallega y los parientes del padrastro, trocado ahora en inflexible dictador, no aprecian ni entienden su amor por la literatura ni su nada tradicional estilo de vida, y los conflictos familiares empiezan de nuevo. El retrato negativo de cómo es vista por la familia y la sociedad gallega que Tula traza para Cepeda es el reverso del de la joven incomprendida, pero independiente y sensitiva, que ha venido construyendo: "decían [. . .] que yo no era buena para nada porque no sabía planchar, ni cocinar, ni calcetar; porque no lababa los cristales, ni hacía las camas, ni barría mi cuarto: Según ellas yo necesitaba veinte criadas y me daba el tono de una princesa. Ridiculizaban también mi afición al estudio y me llamaban la Doctora" (Avellaneda, 1907, p. 36; énfasis en el original). No son solo los parientes, también a un joven con quien se ha comprometido le disgustan su estilo de vida y su entusiasmo por las letras: "Ricafort parecía humillado de la superioridad que me atribuía [. . .]. No gustaba de mi afición al estudio y era para él un delito que hiciese versos" (Avellaneda, 1907, p. 33). Del atolladero la saca su hermano Manuel, quien la convence para seguirle a Andalucía a conocer la familia de su padre, y Tula, a pesar de su renuencia a dejar a su enamorado Ricafort, es feliz de abandonarlo a él y a Galicia.
Con el traslado a Andalucía cesa la narración retrospectiva de su vida/persona para centrarse en el presente y en otro complejo incidente amoroso que ha vivido en Sevilla y que Cepeda conoce. Le asegura que aunque se involucró con este joven no le amaba, y que a veces sentía "un no sé qué de hastío" a su lado, afirmando que "hubiera roto con él, si la compasión no me hubiese inspirado esperar para hacerlo á que se pasase" (Avellaneda, 1907, p. 40). El relato concluye con su ruptura con el joven y la llegada de Cepeda: "Un mes después de la marcha de Méndez Vigo volvió V. de Almonte" (Avellaneda, 1907, p. 42).

La narración de este incidente es intensa; no se trata ya de amores vividos en otros espacios y otros tiempos sino de un evento actual que han vivido ambos. La falta de seguridad de Tula sobre el retrato de inconstante que de sí misma traza al relatar este evento se trasluce en sus nerviosas interrupciones para hablar de sus idas y venidas tras Cepeda al teatro, tertulias y paseos ("no encontré á V. y he sabido que no estuvo" [Avellaneda, 1907, p. 38]); para protestar su amistad incondicional ("Sí; yo ofrezco á V. mi amistad. Pero tenga V. entendido, que puedo ser su amiga sin verle diariamente, ni acaso nunca; y que será V. mi amigo, mi único amigo" [Avellaneda, 1907, p. 38; énfasis en el original]); para suplicar que la comprenda ("iCepeda!, yo prescindo de todo para ser sincera: por Dios!, no me juzgue V. con severidad" [Avellaneda, 1907, p. 39]); y para aseverar que tras tanta desilusión ha decidido no volver a amar ("He jurado no casarme nunca, no amar nunca" [Avellaneda, 1907, p. 42]). Tal desasosiego traiciona su temor al fracaso, su miedo de que el retrato que traza no resulte seductor para Cepeda. Igual recelo refleja la indecisión con que cuestiona en la postdata si debe darle a leer su cuadernillo:

P. D. He leido ésta y casi siento tentaciones de quemarla. Prescindiendo de lo mal coordinada, mal escrita, \&c., ¿Devo dársela á V.? No lo sé: acaso no. Ciertamente no tengo de que avergonzarme delante de Dios, ni delante de los hombres. Mi alma y mi conducta han sido igualmente puras: Pero tantas vacilaciones, tantas ligerezas, tanta inconstancia ¿no deben hacer concebir á aquel, á quien se las confieso, un concepto muy desventajoso de mi corazón y mi carácter? (Avellaneda, 1907, pp. 43-44).

Las dudas e indecisión de Gertrudis estaban justificadas: el dinámico retrato de la voluble, independiente, impulsiva y enamoradiza joven que ha pintado consiguió el efecto opuesto al que anhelaba, desenamorar, si es que alguna vez estuvo enamorado, al tranquilo y materialista Cepeda. ${ }^{9}$ Pese a no surtir el efecto 
deseado, el trato entre ambos se mantuvo firme hasta que él contrajo matrimonio en1854, sin jamás rebasar los límites de la amistad, no obstante la insistencia en seducirle de Tula, evidente en las muchas cartas que le escribió. La que le envía en 1845, viviendo ya en Madrid y tras el fracaso de su relación con Gabriel García Tassara y la muerte de su hija, es representativa. Se retrata en una instantánea que ya no busca cautivarle con la atractiva imagen de la vivaz joven que fue, sino pintándole su triste y amargada persona del presente, al borde del suicidio, aunque le asegura que se retrata solo para desengañarle de la satisfecha imagen con que él la imagina:

Abrumada con el peso de una vida tan llena de todo, escepto de felicidad; resistiendo con trabajo á la necesidad de dejarla; buscando lo que desprecio, sin esperanzas de hallar lo que ansio; adulada por un lado, destrozada por otro; lastimada de continuo por esas punzadas de alfiler, con que se venga la envidiosa turba de mugeres envilecidas por la esclavitud social; tropezando sin cesar en mi camino con las bajezas, con las miserias humanas; cansada, aburrida, incensada y mordida sin cesar hé aquí un bosquejo de esta mi ecsistencia, que tan fausta y brillante te finges.

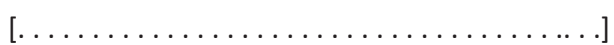

Ya lo ves: nada grato puedo decirte: en otros días buscaba un corazón, que recibiese el mío: ahora no busco más que los medios de aturdirle ó aniquilarle. [...]

Sin embargo, sabes que te quiero, y que con estas insulsas ó amargas líneas, te envío un sentimiento, un afecto de inalterable amistad. (Avellaneda, 1907, pp. 91-92).

Menos exaltada pero igualmente insistente en despertar el interés de Cepeda, apelando de nuevo a su compasión, es el breve retrato que le esboza en 1847, muerto ya su primer marido. Se duele de que él no pueda venir a Madrid, y le describe el desánimo que la abruma y su cambiada persona que tal vez él no reconocería, y que necesita de su presencia a su lado:

Acaso no me conocerías ya: he envejecido veinte años en estos siete, que han pasado. Mi alegría huyó para no volver: desapareció aquella coquetería, que alguna vez te dio enfado, pero acaso era lo que más te agradaba en mí; porque tal es el corazón del hombre. Todo pasó, todo, como nuestros sentimientos de entonces, y resta de la Tula, que conociste, una sombra pálida y fría, que va por momentos diafanándose más. ¿Quédame siquiera el talento? No lo sé; pero siento que se apagó la última chispa de la creadora llama de la poesía. [. . . ]

Te hago un retrato, que de seguro no despertará en tílos deseos de volver á verme. Sin embargo, escucha: ven: deja por un mes siquiera ese clima de juventud y ardores: ven bajo el templado y con frecuencia nublado cielo de Castilla. (Avellaneda, 1907, pp. 96-97).

Cepeda no acudió al reclamo de Gertrudis, las cartas entre ellos se fueron espaciando y cesaron cuando él contrajo matrimonio ${ }^{10}$. El lector de estas cartas y del cuadernillo no necesita demasiada perspicacia para observar que Avellaneda vive los retratos que pinta de sí misma, construyéndose con toda la sinceridad y pasión de que es capaz. Se puede aducir que literaturiza su vida y su persona, pero es precisamente la literatura lo que permite que se viva en esas páginas que ilustran su seducción de Cepeda.

De distinta índole es otro retrato que esboza en 1843 , por la misma época de sus cartas a Cepeda. Lo escribe para Antonio Neira de Mosquera, quien le había solicitado información biográfica para un artículo que publicó en 1844 en el periódico literario El Arlequín (Cotarelo y Mori, 1930, pp. 87-90). El carácter público de la estampa que diseña la mueve a construirse sin los previos excesos dramáticos, captándose ahora en la ejemplar postura de Doña Gertrudis-irreprochable-escritora-romántica: independiente, excepcional, de noble abolengo y llana en su trato:

Soy soltera, huérfana pues perdí a mi padre siendo muy niña y mi madre pertenece a un segundo marido. Soy sola en el mundo; vivo sola, escéntrica bajo muchos conceptos. Aunque no ofendo a nadie tengo enemigos, y aunque nada ambiciono se me acusa de pretensiones desmedidas.

Mi familia pertenece a la clase que llaman noble, pero yo no pertenezco a ninguna clase. Trato lo mismo al Duque que al cómico. No reconozco otra aristocracia que la del talento. (Cotarelo y Mori, 1930, p. 430; énfasis en el original).

Diferente es también otro retrato, íntimo y seductor de nuevo, que escribe años más tarde a Antonio Romero Ruiz, con quien mantuvo una liaison amorosa en la primavera de 1853 . El contacto se inicia en una especie de juego cuando Romero Ruiz le dirige una carta firmada por Armand Carrell, desafiándola a que acierte su identidad. El juego se extiende a través de cuarenta y cinco cartas que van progresando de entretenido acertijo a coqueteo intrigante y a convenio amoroso para terminar en una eventual y firme amistad. Los retratos que Tula esboza durante 
esta evolución son varios, pero me interesa comentar uno en particular porque elucida tanto la postura ambigua de Avellaneda vis-à-vis los códigos sociales de su época como su porfiada búsqueda del amor ideal. Lo escribe en la carta número diez, cuando ya conoce la identidad de Romero Ruiz e intenta establecer una relación romántica que no deshonre ni su prestigiosa persona ni su posición social. Para lograrlo se retrata primero en la postura de Gertrudis-mujer-independiente-famosa y prudente, una mujer que entiende la importancia de preservar su reputación, para lo que necesita mantener sus amores a nivel platónico e íntimamente secreto. Se retrata y retrata sus circunstancias sin ambages:

Mi posición es indudablemte [sic] la más libre y desembarazada que puede tener un individuo de $\mathrm{mi}$ sexo en nuestra actual sociedad. Viuda, poeta, independiente por carácter, sin necesitar de nadie, ni nadie de mí, con hábitos varoniles en muchas cosas, y con edad bastante para que no pueda pensar el mundo que me hacen falta tutores, es evidente qe. estoy en la posición mas propia pa. hacer cuanto me dé gana. (Avellaneda, 1975, p. 31).

La independencia y seguridad que proclama es firme. No obstante, pronto subvierte la imagen de su independencia "no hay en la tierra persona que se encuentre mas comprimida que yo, y en un círculo mas estrecho". Su libertad es engañosa, añade, porque la ata el respeto hacia su madre, a quien ha hecho sufrir con sus excentricidades y a quien no quiere volver a herir, y por el respeto que le merece el nombre que le ha dado su ya muerto marido, "el mas noble de los hombres". Le insta pues a mantener secretos sus amores, "no quiero, ni creo qe. tu quieras, deshonrar nuestros vínculos llevandolos à un terreno de fango y de miseria, con todo, amigo mio, siento que la publicidad me seria muy dolorosa y me haría muy infeliz" (Avellaneda, 1975, p. 31). Agrega que la publicidad la haría sentirse culpable de ultrajar la reputación de su ya muerto esposo, y confiesa que de soltera no tuvo tales reparos "por ostentación de libertad; ahora, viuda, no me creo autorizada a hacerlo" (Avellaneda, 1975, p. 31). El retrato que traza de su persona y circunstancias y su ruego resultan verosímiles y sinceros, y con seguridad lo son. No obstante, la digna y moderada Gertrudis de este retrato contradice su postura mesurada en las próximas líneas, adoptando otra pose, melodramáticamente romántica, que traiciona su afán de seducir a Romero Ruiz con palabras exaltadas que recuerdan las de su pasado apasionamiento por Cepeda: "iQue no pudiera yo irme contigo à un desierto de America!... iQue no pudiera romper por todo, y arrojar à la faz del mundo esta corona de oropel y de espinas que llaman nombradía, y hacerme tan ignorada, tan desconocida qe. solo tu, tú solo, amigo mio supieras mi existencia y la amases...!" Y le expresa su deseo de hallar en él a ese amado que ha buscado con tanta insistencia: "Antonio, en nombre del cielo, no te parezcas en nada à los hombres: necesito creer que eres un ser único, porque aborrezco todo lo que conozco: porque me siento mal entre aquellos qe. osan llamarse mis semejantes" (Avellaneda, 1975, p. 32). Su doble retrato, el de la honesta y digna autora Gertrudis Gómez de Avellaneda de Sabater que escribe en la primera parte de su carta y el de Tulaapasionada-amante-romántica con que a manera de un palimpsesto lo difumina en la segunda, aunque paradójicamente contradictorio, es consecuente con las visiones pública y privada de sí misma que en ese momento dibuja para seducir a su potencial amante.

A excepción del retrato a Neira, la pasión con que Avellaneda vive y escribe los retratos íntimos del cuadernillo y de las cartas contrastan con los que construye en su poesía, más casuales, juguetones casi. Son retratos circunstanciales, escritos para superponer otra visión de sí misma sobre la que trata de imponerle su interlocutor. Aunque tal vez sea injusto calificar de juguetones los "Cuartetos" que compuso en 1846 para su novio Pedro Sabater, desmontando la semblanza que de ella ha construido, y que por la mesura de su expresión amorosa hacia su nuevo amado merece ser contrastado con las apasionadas palabras que en el cuadernillo le dirigió a Cepeda. En cierto modo, el retrato que pinta refleja la angustia que la embarga cuando tres meses después de romper con el sevillano hace planes para casarse con Sabater. El poema comienza rechazando la exactitud del retrato que su novio le ha escrito, admitiendo que es bello, pero no es ella: "Toques valientes, vivo colorido, / Dignidad de expresión, conjunto grato... / Todo es bello ioh amigo! El parecido / Sólo le falta a tan feliz retrato" (Avellaneda, 1869, p. 210; énfasis en el original). Subraya que los rasgos idealizados con que él la pinta provienen de sí mismo y no emanan de ella, y que teme que el paso del tiempo le hará ver su error: "iDesdichada de mí si el tiempo alado / Se lleva en pos el fúlgido atavío, / Y hallais un dia, atónito, turbado, / El esqueleto descarnado y frio!..." (Avellaneda, 1869, p. 211). Dice asombrarse de que espere encontrar ventura en alguien tan abatido como ella, advirtiéndole que aunque como él nació para admirar y amar, ya no cree en nada: "Yo, como vos, para admirar nacida / Yo, como vos, para el amor creada; / Por admirar y amar diera 
mi vida... / Para admirar y amar no encuentro nada" (Avellaneda, 1869, p. 211). Pero le confiesa que si deposita su fe en Dios y la acepta sin idealizaciones, ella será la fiel compañera que compartirá sus penas, y podrán socorrerse mutuamente con la ayuda del cielo:

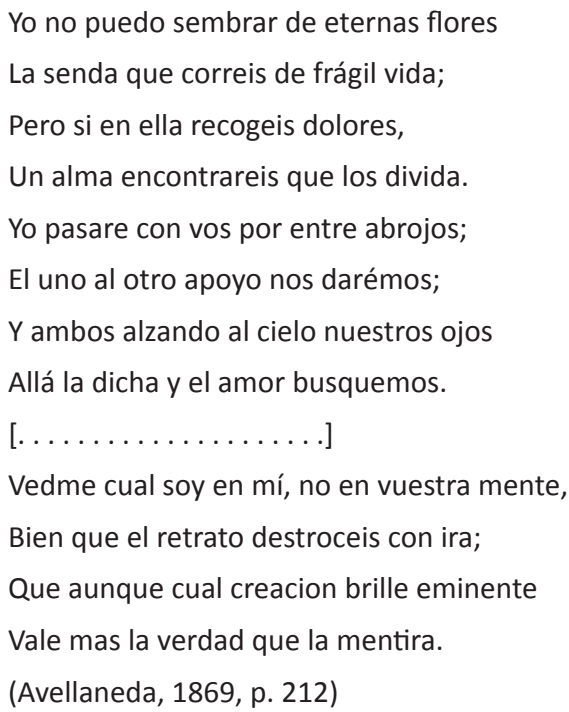

La mesura del retrato es extraordinaria y denota un sentimiento amoroso desapasionado, muy distinto del que expresó en el cuadernillo. En su admonición, "Vedme cual soy en mí, no en vuestra mente", repercute su propia idealización de Cepeda.

Más literario y menos íntimo resulta otro retrato que traza ese mismo año en uno de sus poemas más antologados. Lo titula simplemente "Romance" y en él contesta a otro, que le ha enviado una señorita. Avellaneda busca desconstruir la imagen de la poeta insigne y laureada con que la representa su retratista y superponerle otra de aparente humildad, ideada de acuerdo a la noción romántica de que el ser poeta es un don de los hados, sin contribución alguna de esfuerzo personal: ${ }^{11}$

$$
\begin{aligned}
& \text { No soy maga, ni sirena, } \\
& \text { Ni querub ni pitonisa, } \\
& \text { Como en tus versos galanos } \\
& \text { Me llamas hoy, bella niña. } \\
& \text { Gertrudis tengo por nombre, } \\
& \text { Cual recibido en la pila, } \\
& \text { Me dice Tula mi madre } \\
& \text { Y mis amigos la imitan. } \\
& \text { Prescinde, pues, te lo ruego, } \\
& \text { De las Safos y Corinas, } \\
& \text { Y simplemente me nombra }
\end{aligned}
$$

Gertrudis, Tula, ó amiga.

(Avellaneda, 1850, p. 243; énfasis en el original).

A esta imagen inicial de la poeta sin pretensiones, un ser escogido por el hado, le agrega una segunda de corte feminista, indicando que contrario a lo aducido por su pintora, las cualidades nobles de su personapoeta prueban que también la mujer es capaz de vivir y sentir los más elevados ideales:

$$
\begin{aligned}
& \text { Contra tu secso te indignas, } \\
& \text { Y de maligno lo acusas, } \\
& \text { Y de envidioso lo tildas, } \\
& \text { En mí pretendo probarte } \\
& \text { Que hay en almas femeninas } \\
& \text { Para lo hermoso entusiasmo, } \\
& \text { Para lo bueno justicia. } \\
& \text { (Avellaneda, 1850, p. 243). }
\end{aligned}
$$

Niega después que la fuerza física (el hombre) sea muestra de mayor capacidad espiritual:

$$
\begin{aligned}
& \text { No son las fuerzas corpóreas } \\
& \text { De las del alma medida; } \\
& \text { No se encumbra el pensamiento } \\
& \text { Por el vigor de las fibras. } \\
& \text { (Avellaneda, 1850, p. 244). }
\end{aligned}
$$

Y pasa a recalcar su humildad y la espontánea naturalidad con que su poesía canta a la vida:
No, no aliento ambición noble,
Como engañada imaginas,
De que en páginas de gloria
Mi humilde nombre se escriba.
Canto como canta el ave,
Como las ramas se agitan,
Como las fuentes murmuran,
Como las auras suspiran.
Canto porque al cielo plugo
Darme el estro que me anima,
(Avellaneda, 1850, p. 244).

Es la suya sin embargo, añade, una poesía portentosa, porque no obstante su naturalidad, es tan vigorosa como la de un hombre por estar colmada de experiencias humanas, de ideas y de sentimientos nobles, y de ansias trascendentes:

\section{Canto porque hay en mi pecho \\ Secretas cuerdas que vibran}


A cada afecto del alma,

A cada azar de la vida.

Canto porque hay luz y sombras,

Porque hay pesar y alegría,

Porque hay temor y esperanza,

Porque hay amor y hay perfidia.

Canto porque existo y siento;

Porque lo grande me admira,

Porque lo bello me encanta,

Porque lo malo me irrita.

Canto porque vé mi mente

Concordancias infinitas,

$Y$ placeres misteriosos,

$Y$ verdades escondidas.

(Avellaneda, 1850, p. 244).

Tula termina su semblanza de mujer-poeta-romántica-innatamente-viril afirmando su humildad.

Si canta es por ser poeta, una poeta humana, sencilla, sin ninguna cualidad sobrenatural, que escribe movida por su estro, sin acertar a discernir el valor o los significados ocultos de su poesía:

Canto sin saber yo propia

Si algo el canto significa,

Y sí al mundo que lo escucha

Asombro ó lástima inspira.

El ruiseñor no ambiciona

Que lo aplaudan cuando trina,

Latidos son de su seno

Sus nocturnas melodías.

Modera, pues, tu alabanza,

$Y$ de mi frente retira

La inmarchitable corona

Que tu amor me pronostica.

Premiando nobles esfuerzos

Sienes más heroicas ciña

Que yo al cantar solo cumplo

La condición de mi vida.

(Avellaneda, 1850, p. 245).

A estos retratos de Tula-poeta-romántica-innatamente-viril del "Romance", de Tula-esposa-ejemplar de los "Cuartetos", de Gertrudis-digna-y-honesta versus Tula-amante-apasionada de la carta a Romero Ruiz, de Dña. Gertrudis-irreprochable-escritora-ro- mántica de El Arlequín, y de Tula-amante-apasionada del cuadernillo, hay que agregar el de La Peregrinaambivalente-cubana/española que delinea en 1850 en un poema titulado "A la poetisa habanera Señora Doña Luisa de Franchi Alfaro", contestando el reclamo de cubanía que le hace su compatriota. Luisa había iniciado su poema subrayando la ausencia de Cuba de Avellaneda, indagando si no echaba de menos su patria: "Ave canora de tus patrios lares, / A otras regiones remontaste el vuelo: / ¿Olvidaste de Cuba los palmares, / Su ardiente sol y flores de su suelo?"; y concluía subrayando la tristeza de su patria ante su ausencia, e instándola a que regresase para cantarla: "Tu ausencia llora Cuba, que enojosa / Le fue al verte partir á otros confines. / Ven, rosa de los trópicos galana, / Ven a lucir en la pradera indiana" (FranchiAlfaro, 1850, p. 49). En su respuesta, Tula también coloca en primer plano su faceta de indiana, peregrina en tierra ajena, pero lo hace para subrayar la incontrovertible dualidad cubana-española de su persona, su imposibilidad de separarlas. Su ambivalencia se inscribe en la pregunta con que inicia el poema, cuestionando por qué la insta a regresar cuando Luisa ya está en Cuba y puede cantarla:
¿Por qué á la indiana pradera,
Mansion de luz y de flores,
Anhelas que mi arpa austéra
Vaya á exhalar la postrera
Vibracion de mis dolores?
Para ese Eden de delicia,
¿Por qué mi canto reclama
Luisa, tu voz, si propicia,
Bajo el sol que lo acaricia
La casta Musa te inflama?
(Avellaneda, 1850, p. 306; énfasis en el original).

Avellaneda prosigue su argumento alabando el arte con que Luisa pinta la Isla, asegurándole que sus cantos son tan vivos que puede oler sus perfumes, escuchar el susurro de sus palmares y oír el canto de sus pájaros:
¡Ay! Paréceme que aspiro
En esos blandos cantares
Auros de los patrios láres,
$Y$ hasta que escucho el suspiro
con que mecen los palmares.
$Y$ percibir imagino
olor de vírgenes montes, 
$Y$ que entre albor matutino

Me llega el éco argentino

De los canores sinsontes.

(Avellaneda, 1850, p. 307).

Le advierte sin embargo que aunque le agradece las vivencias que sus cantos han despertado en ella, es precisamente la rememoración evocada por tales cantos lo que la afirma en su decisión de que no debe ni puede volver a cantar a esa hermosa Cuba en sus versos, amargos ahora: "No esperes que la voz mia / [. . . ] / Lance en agreste armonía / Ayes de un alma doliente". En vez, le dice, tú que eres joven e inocente y vives en un mundo libre "de impuros vapores", eres la más apropiada para hacerlo: "Canta esa pátria florida / Joya del cétro español... [. . .] // Miéntras que yo mis pesares / lamento triste á la orilla / del humilde Manzanares" (Avellaneda, 1850, pp. 307-308). Tristeza o nostalgia que recuerda la de su despedida de su tierra en "Al partir", en 1836, que la identifica con la Otra Cuba esencial, no con las palmas, los ritmos y la alegría frívola que es costumbre asociar con la Isla. En Cuba, prosigue Tula, nació a la vida y su amor y nostalgia por ella son parte de sí misma, pero en España nació a la fama y su gratitud es constante. Su esencia, como han señalado Adriana Méndez Rodenas (1997) y Milena Rodríguez (2012b), es híbrida: pertenece a dos patrias y sus dos patrias son parte de ella. La desubicación que sugiere su doble identidad coloca en primer plano la figura de Tula-La Peregrinadoblemente-extranjera:

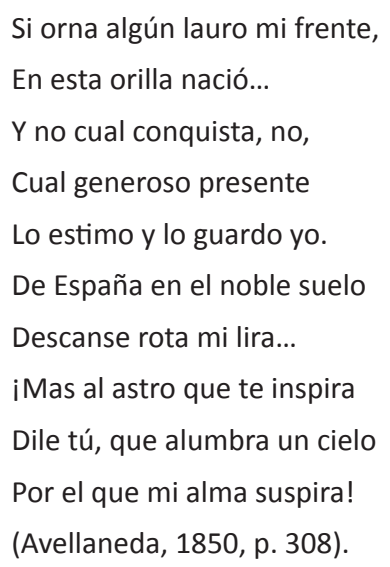

El pesimismo que sugiere el dolor que dice dominar sus versos, indica el decaimiento vital que la movería a abandonar la poesía ese mismo año de 1850, y a retratarse en la estampa de Tula-poeta-estéril, con que pone fin a las Poesías (1850) en "El último acento de mi arpa"12.

\author{
No hay ya para mi poesía \\ De vagos dolores, \\ De ardientes amores, \\ De inmenso anhelar. \\ La luz de mi genio se vela, \\ Se apaga mi acento, \\ No admiro, no invento, \\ No puedo cantar. \\ (Avellaneda, 1850, p. 309).
}

No obstante la total negatividad de la estampa que pinta, Avellaneda delata su ambivalencia ante su decisión de abandonar la poesía en otras declaraciones que dirige a su amiga, confesando por un lado, que tal vez en este poema pulse las mejores cuerdas de su lira, su canto del cisne:
¡Tal vez, como el cisne, mi genio
Dará en su agonía
Mas dulce armonía, i
Sonido mejor!
¡Tal vez como el sol, que en ocaso
Mas bello parece,
La voz que enmudece
Mas grata será!
(Avellaneda, 1850, p. 310).

Y proponiendo por otro lado, que si ha sabido tañer con acierto las cuerdas de su lira, ambas se eternizarán en sus versos, admisión implícita de que no juzga su poesía tan inepta como proclama:
Mas si algún eco del arpa,
Que hoy á romper me decido,
Logra vencer al olvido
$Y$ al voraz tiempo burlar,
A par de mi nombre tu nombre querido
Por siglos futuros se oirá resonar.
(Avellaneda, 1850, p. 312).

La ambigüedad con que Tula se despide de la poesía predice la ambigüedad con que acataría su decisión. Es cierto que nunca volvería a tañer la lira de la poesía lírica con igual dedicación que en su juventud, pero también lo es que compondría decenas de poemas más, como se aprecia en la edición definitiva de su poesía de 1869. Lástima que en ninguno de ellos se volviese a retratar en posturas representativas de las sucesivas experiencias que habría de vivir su idiosincrásica persona. 
La lectura de los retratos que sí escribió, los que esboza en la Autobiografía y en las cartas íntimas, me llevan a coincidir en parte con lo señalado por Lucía Guerra en cuanto a la imagen y a la estética romántica con que Tula construyó su persona: "es evidente que ella se concebía a sí misma como uno de estos seres excepcionales y que, ideológicamente, su concepción del amor era afín con aquella de los numerosos escritores románticos que leyó en su niñez" (Guerra, 1985, p. 712). Pero es innegable, además, que estos retratos están pensados para seducir a los hombres que ama, pintándose en la imagen de lo que en distintos momentos de su vida/escritura era para ella la mujer romántica ideal, ese "ser excepcional", como lo define Lucía Guerra, que por desgracia para Tula, y como sugieren sus repetidos fracasos, parece no haber coincidido nunca con la más tradicional imagen del "ángel del hogar" que privilegiaron sus des- tinatarios. La uniformidad de la estampa romántica de la voluntariosa-mujer-amante-ideal con que Tula se escribió en estos retratos y que vivió a plenitud en su experiencia cotidiana es incuestionable. La que traza en sus poemas exhibe mayor variedad y menos obsesión, sugiriendo que al escribir sus retratos en verso no le iba la vida en ellos; de hecho, no era ella quien escogía su postura sino que le había sido impuesta desde fuera y escribía para rectificarla. Aun así, tanto estos retratos en verso, como los que ideó en sus prosas autobiográficas, representan genuinas versiones de su multifacética persona y personalidad históricas en determinados momentos de su vida, lo que me lleva a concluir que si las ficciones de su yo resultan patentemente veraces es debido precisamente a la sabia mezcla de historia y de imaginación con que Gertrudis Gómez de Avellaneda supo transformar en literatura su vida y su persona cotidianas.

\section{NOTAS}

1 Defino el (auto)retrato literario personal como un texto caracterizado por su relativa brevedad, por estar escrito en prosa o en verso y por plasmar de manera iconográfica, es decir, subjetiva, momentánea y unilateral, aunque no necesariamente visual, la esencia (genio y figura) propia o ajena; son textos que identifican de manera explícita al retratado, estableciendo un pacto con el lector que como ha indicado Philippe Lejeunne facilita la lectura biográfica.

2 Reproduzco los textos de Avellaneda respetando las particularidades de su escritura, y recordando la advertencia de Emilio Cotarelo y Mori de que Avellaneda "no sabía ortografía" (1930, p. 38). Soy consciente de que varios críticos, entre ellos Elena Catena, Roxana Pagés Rangel, Milena Rodríguez Gutiérrez (2012a), Ángeles Ezama Gil y Roberto Méndez, impugnan la exactitud histórica y textual de sus escritos autobiográficos, subrayando las manipulaciones de sus editores. Mucho antes también Cotarelo y Mori había cuestionado que Cruz de Fuentes no publicara todas las cartas en la edición de 1907: "No entraremos en la cuestión de si es lícito, tratándose de personas a quienes pudieron conocer otras aún vivas y con parientes también vivos, publicar docu- mentos privados y secretos o en ningún modo destinados a la publicidad. [. . . ] Pero lo que no debió haberse hecho fué ocultar ninguna" (Cotarelo y Mori, 1930, p. 36).

3 Antón Arrufat problematiza las fronteras entre vida y literatura en la obra de Avellaneda, preguntándose hasta qué punto "su persona, si puedo expresarme así, se ha objetivizado en la escritura", al haber escrito en una época en que "lo que Ilamamos 'vida', buscó expresarse mediante la palabra" (Arrufat, 2008, pp. 36-37).

4 Ezama Gil concluye que ninguno de los textos autobiográficos de Avellaneda es una auténtica autobiografía: "Todos los textos de Gertrudis Gómez de Avellaneda que vengo comentando pueden sin duda motejarse de 'autobiográficos' pero ¿puede aplicarse a alguno de ellos la denominación de 'autobiografía' strictu senso? Creo que no" (Ezama, 2009 , p. 11). La hibridez de tales textos es incuestionable y los acerca al retrato literario.

5 Para Ezama, el concepto idealizado del amor que Tula representa en el yo del cuadernillo refleja la dificultad para hallar al amado ideal que encuentra también en el mundo cotidiano: "[su] elevada con- cepción del amor hace imposible concretarlo en un individuo determinado; de ahí su oposición al matrimonio y la libertad amorosa con que se expresó a lo largo de su vida, aunque, finalmente, se casara en dos ocasiones" (Ezama, 2009, p. 4).

6 La veracidad que protesta la persona autobiográfica de Avellaneda es sincera. La ficcionalización o romantización que refleja el yo de la protagonista no socava su verismo ingénito. De hecho, la verdad histórica de su autobiografía es incuestionable; en ningún momento inventa eventos, espacios, ni personajes, aunque la ficción inherente en cualquier tipo de escritura tiña sus retratos de literatura.

7 Carmen Bravo-Villasante subraya la importancia del aspecto de penitente o romero de la personalidad de Avellaneda: "Con el tiempo ella siempre se verá como peregrina en la tierra, fuera de su verdadera patria celeste [...] que alguna vez será el cielo de origen, otras la isla de Cuba abandonada" (BravoVillasante, 1967, p. 27). Antón Arrufat ofrece otro posible significado de este sobrenombre: "Se llamaba a sí misma 'la franca india' y 'la peregrina'--en la acepción de 'extraña', 'rara'--con cierto orgullo y hasta con cierta insolencia" (Arrufat, 2008, p. 59). 
8 Roberto Méndez subraya la faceta melancólica del yo del cuadernillo: "todo el texto está condimentado por una especial atracción hacia las situaciones dramáticas, con una atracción casi masoquista por el dolor y lo lacrimoso". Indica también que la autora hace un retrato espiritual de sí misma cuando describe a su prima comparándose con ella (Méndez, 2007, pp. 71-72).

9 Para Cruz de Fuentes, la inteligencia superior de Avellaneda amedrantó a Cepeda: "La revolución operada en su espíritu fué súbita y dolorosa: el ídolo cayó de su profanado altar y se destruyó el culto. ¿Cual fué la causa de tanta desventura? No lo sabemos á ciencia cierta. Los celos tal vez; la pasión absorbente, avasalladora, que no conocía límites, de la franca india, como graciosamente á sí propia se llamaba la simpática Tula; y la templanza sostenida del Sr. Cepeda ante el temor instintivo de entregarse con armas y bagaje á aquella inteligencia poderosa, que algún día podría anularle con su superioridad indiscutible, debieron hacer el milagro. El hecho es, que en los primeros meses del año 1840 , pierden las cartas su tinte apasionado, para reducirse paulatinamente á una correspondencia entre dos amigos muy íntimos, muy queridos, pero nada

\section{BIBLIOGRAFÍA}

Arrufat, A. (2008). Las máscaras de Talía. Matanzas: Ediciones Matanzas.

Bravo-Villasante, C. (1967). Una vida romántica; la Avellaneda. Barcelona: $\mathrm{E}$ [ditora] $\mathrm{H}$ [ispano] $\mathrm{A}$ [mericana].

Cotarelo y Mori, E. (1930). La Avellaneda y sus obras. Ensayo biográfico y crítico. Madrid: Tipografía de Archivos.

Darío, R. (1920/1896). Los raros. Madrid: Mundo Latino.

Dufour, H. (1997). Portraits en phrases. Les recueils de portraits littéraires au $X I X^{e}$ siécle. Paris: Presses Universitaires de France.

Ezama Gil, A. (2009). Gertrudis Gómez de Avellaneda: Un siglo de manipulación e invención en torno a su autobiografía (1907-2007). Decimonónica. Journal of Nineteenth Century Hispanic Cultural Production / Revista de Producción Cultural Hispánica Decimonónica 6, 2. Recuperado de http://www.decimononica.org/ más que amigos" (Avellaneda, 1907, p. 5; énfasis en el original).

10 Avellaneda reconoce en una carta a Romero Ruiz que Cepeda nunca correspondió a su amor: "[...] una sola vez he creído amar [...] abrigué largo tiempo un sentimiento enérgico, único de su especie que he sentido. No fuí víctima de un abandono vulgar: mi desgracia consistió en que me dejé subyugar por las cualidades de la inteligencia sin cuidarme de las del corazón. No concebía entonces que pudiera un hombre comprenderlo todo y no sentir nada [...]. Alucinada por la simpatía de las ideas no eché de ver sino tarde, que había en otras regiones de nuestras almas una divergencia absoluta; una inarmonía eterna. Cuando lo conocí mi orgullo me empeñó en un imposible [...]. La lucha comenzó; fue larga; fue terrible; y acabó por cansar a la parte más débil que no era yo. No cesó él de amarme; fué que comencé yo a comprender que no podía haberme ocupado nunca. Murió m amor por último" (Avellaneda, 1975, p. 35; énfasis en el original).

11 Roberto Méndez ha comentado que la afirmación de espontaneidad que Tula expresa en estas estrofas queda desmentida por la revisión continua a que so- metía sus poemas en busca de la forma perfecta (Méndez, 2007, pp. 93-94). Susan Kirkpatrick (1989) señala que las estrofas más citadas ("Canto como canta el ave / Como las ramas se agitan [. . .]") las ha tomado del poema de Lamartine "Le poète mourant", lo que también sugiere su intensa elaboración literaria mientras protesta espontaneidad (p. 185).

12 Avellaneda argumenta en el "Prefacio de la autora", que su "corazón cansado por la desventura" no siente ya las "pasiones ardientes" necesarias para la poesía lírica: "Sin atender mas que á las fechas, publico estas POESIAS con la gradación natural de desarrollo ó detrimento que ha debido tener mi imaginación desde el año de 36, en que comencé á conservar escritos mis desaliñados versos, hasta fines del de 50 , en que rompo para siempre las cuerdas de la lira, que no vibra agradablemente sino en manos de la juventud, al soplo poderoso de las pasiones ardientes. Con treinta y cuatro años, y un corazón cansado por la desventura, me siento incapaz de proseguir la carrera de poeta lírico, y si no abandono completamente el comercio de las musas, solo les pediré en lo sucesivo las graves inspiraciones dramáticas [...]" (Avellaneda, 1850, pp. II-III).
Franchi-Alfaro, H. de y Dávila, L. de (1850). Poesías. Habana: Imprenta de A. M. Dávila.

Gómez de Avellaneda, G. (1850). Poesías de la Exma. Sra. Gertrudis Gómez de AveIlaneda de Sabater. Madrid: Imprenta Delgrás Hermanos. Recuperado de http://babel.hathitrust.org/cgi/pt?id=u c1.31822038202933; view=1up;seq=17

Gómez de Avellaneda, G. (1869). Obras literarias de la Señora Doña Gertrudis Gómez de Avellaneda (tomo I). Poesías líricas. Madrid: M. Rivadeneyra.

Gómez de Avellaneda, G. (1907). La Avellaneda. Autobiografía y cartas hasta ahora inéditas; con un prólogo y necrología de Lorenzo Cruz de Fuentes. Huelva: Imprenta y Papelería de Miguel Mora. Recuperado de http://archive.org/details/ laavellanedaauto00cruz

Gómez de Avellaneda, G. (1975). Cartas inéditas existentes en el Museo del Ejército. Madrid: Fundación Universitaria Española.
Gómez de Avellaneda, G. (1989). Poesías y epistolario de amor y de amistad. Madrid: Castalia / Instituto de la Mujer.

Guerra, L. (1985). Estrategias femeninas en la elaboración del sujeto romántico en la obra de Gertrudis Gómez de Avellaneda. Revista Iberoamericana, 132-133, pp. 707-722.

Kirkpatrick, S. (1989). Las Románticas: Women Writers and Subjectivity in Spain, 1835-1850. Berkeley: University of California Press.

Lejeunne, P. (1971). L'Autobiographie en France. Paris: Librairie Armand Colin.

Méndez, R. (2007). Otra mirada a La Peregrina. La Habana: Letras Cubanas.

Méndez Rodenas, A. (1997). Mujer, nación y otredad en Gertrudis Gómez de Avellaneda. En Campuzano, L. (ed.). Mujeres latinoamericanas: Historia y cultura: siglos XVI al XIX (tomo II). La Habana: Casa de las Américas; México, DF: Uni- 
versidad Autónoma Metropolitana-Iztapalapa, pp. 167-179.

Pagés-Rangel, R. (1997). Del dominio público: itinerarios de la carta privada. Amsterdam, Atlanta, GA: Rodopi.

Pastor, B. (2000). Identidad femenina en e cuadernillo autobiográfico de Gertrudis Gómez de Avellaneda. Revista de la Biblioteca Nacional José Martí, 1-2. Recuperado de http://www.pprincipe. cult.cu/articulos/identidad-femeninacuadernillo-autobiografico-gertrudisgomez-avellaneda.htm

Rodríguez Gutiérrez, M. (2012a). La correspondencia de Gertrudis Gómez de Ave- llaneda a Cepeda: problemas en torno a la transmisión del texto. En Entre el cacharro doméstico y la Vía Láctea. Poetas cubanas e hispanoamericanas. Sevilla: Renacimiento, pp. 40-64.

Rodríguez Gutiérrez, M. (2012b). La reina y la libertad: reflexiones en torno al poema «A S.M. La Reina, cuando la declaración de su mayoría», de Gertrudis Gómez de Avellaneda. En Entre el cacharro doméstico y la Vía Láctea. Poetas cubanas e hispanoamericanas. Sevilla: Renacimiento, pp. 65-79.

Selimov Roselló, A. (1999). Introducción. En Gertrudis Gómez de Avellaneda.
Autobiografía y epistolarios de amor. Newark (Delaware): Juan de la Cuesta, pp. 7-56.

Volek, E. (2004). Introducción. En Gertrudis Gómez de Avellaneda. Tu amante ultrajada no puede ser tu amiga. Cartas de amor. Novela epistolar. Madrid: Fundamentos, pp. 9-47.

Zatlin Boring, P. (1981). Una perspectiva feminista sobre la confesión de la AveIlaneda. En Zaldívar, G. y Martínez de Cabrera, R. (eds.). Homenaje a Gertrudis Gómez de Avellaneda. Miami: Universal, pp. 93-98. 